\title{
Background and Motivation of Students Studying a Native American Language at the University Level
}

\author{
Juliet L. Morgan
}

\begin{abstract}
This study examines the background and motivations of first through fourth semester university-level Native American language learners at the University of Oklahoma. A survey of ten questions collected data concerning demographic information, students' home language background, their favored classroom activities, motivations for taking the course, and intended future study of the language. The survey was designed to discover who is enrolling in Cherokee, Cheyenne, Choctaw, Muscogee Creek, and Kiowa at the University of Oklahoma, and why these individuals choose to study these languages. The analysis distinguishes heritage language learners from second language learners. The results of the study work toward an understanding of whether these students are motivated by integrative or instrumental factors and how understanding these students' backgrounds and motivations can inform teaching methods.
\end{abstract}

\section{Background and Motivation of Students Studying a Native American Language at the University Level}

The University of Oklahoma (OU) teaches five Native American languages (NALs) that fulfill college foreign language credit. These languages are Cherokee, Cheyenne, Choctaw, Muscogee Creek, and Kiowa. In my first semester as a Master's student at OU, I enrolled in a Cherokee language class. Later, I became the teaching assistant to the Native American Language Program, responsible for helping the instructors create course materials. Curious to understand who the students studying NALs are, I designed a ten-question survey on student language backgrounds, language learning motivation, and future intentions of language study, which I gave out to the students during the fall of 2010. To my knowledge, there have been no other studies on the background and motivations of university-level NAL students, a group of learners who are overlooked in the study of university language learners and in the discussion of language revitalization. A more informed understanding of their backgrounds and motivations can contribute to a better understanding of their language learning needs.

\section{Background}

The five languages involved in this survey are all spoken in Oklahoma. There are a total of forty NALs historically or currently spoken in Oklahoma, representing eleven language families. The large number of languages is due to the removal of many tribes to Indian Territory during the nineteenth century. For example, Kiowa and Cheyenne were spoken in 
Oklahoma pre-removal period, but the Cherokee, Choctaw, and Muscogee Creek tribes (among others) were forcibly removed to the Indian Territory. It is impossible for OU to offer all of the indigenous languages of Oklahoma, and as with other areas of high linguistic diversity, finding enough funding and support to teach a large number of endangered languages is a huge challenge. Since 1991, the University of Oklahoma has offered sustained funding and support for five Oklahoman NALs through the Native American Language Program. This year marks the twentieth year of teaching Cherokee, Choctaw, and Kiowa, while Muscogee Creek has been taught for eighteen years and Cheyenne for ten years.

All Oklahoman NALs are critically endangered. Of the forty NALs spoken in Oklahoma in 1900, 53\% (or 21 languages) have no fluent first language speakers left today (Linn, 2011). The Cherokee language (Iroquoian) has an estimated 8,000 native speakers, but no sustainable speaker population under 45 (Linn, 2011). Choctaw (Muscogean), the second most populous tribe, has an estimated 1,000 fluent speakers still in Oklahoma (Linn, 2011). Cheyenne (Algonquian) is estimated to have only 20 fluent speakers in Oklahoma today and Muscogee Creek (Muscogean) has approximately 3,000 fluent speakers over the age of 64 (Linn, 2011; Martin \& Mauldin, 2001). Kiowa (Kiowa-Tanoan) currently has approximately sixty fluent speakers left (Linn, 2011). The five languages taught at OU exemplify the diverse distribution of current NAL situations in Oklahoma.

A variety of interrelated reasons are identified as having a role in the decline of NAL use in the United States, including contact, colonization, warfare, forced relocations, and intermarriages with speakers of other languages (Hinton, 2008; McCarty, 2008). In the late $19^{\text {th }}$ and early $20^{\text {th }}$ centuries, boarding schools actively sought to erase indigenous languages and this period is often cited as one of the most prominent causes of language loss among Native Americans (McCarty and Zepeda, 2010). Today, assimilation into American society and the overwhelming amount of contact with English has greatly increased the rate of loss in many NAL communities. The endangered status of NALs gives them a unique position in language learning, and programs like the one at OU are rare.

The Native American Language Program at OU was started in 1991 in the Department of Anthropology. Originally, the program involved an elder native speaker and a professionally trained linguist teaching together in the classroom. Each language team had to create their own teaching materials and curriculum, as at that time there were no available textbooks or teaching materials. Even today, only Cherokee, Choctaw, and Muscogee Creek have published textbooks. The classes were originally offered at night and not for foreign language credit, making them more similar to community classes than typical university-level language classes. One of the major challenges to the program was creating enough materials to teach the classes for two semesters. After one year, the classes passed the application to be taught for undergraduate foreign language credit and moved to daytime hours, changes which attracted a larger number of students. The program evolved to have native speakers with previous teaching experience (such as teaching any subject in a public school or teaching community classes in the language) taking full control of teaching the classes.

At the time the survey was administered in fall 2010, the program as a whole offered four semesters of Cheyenne and Muscogee Creek and three semesters of Cherokee, 
Choctaw, and Kiowa. The first and second semesters of Cherokee, Choctaw, and Muscogee Creek are five hours per week while all of the other classes (all levels of Kiowa and Cheyenne and all third and fourth semester levels of all the languages) are three hours per week. Today the program has twelve instructors: three Cherokee, one Cheyenne, three Choctaw, two Muscogee Creek, and three Kiowa. All but four of the instructors are native speakers. Since its inception, the program's instructors have shifted from a team of elder native speakers and linguists to native speakers with teaching experience, and now the most recently hired instructors are younger, competent second language speakers and two of them have a degree or are getting a degree in language education. As the elder instructors retire the trend of hiring second language speakers may continue, especially given the small numbers and elderly ages of most native speakers in Oklahoma.

The decision to teach Native languages is not simple. Nonimmersion classes offered to adult learners are not expected to be successful in creating new speakers of the language (Hinton, 2011). While the inclusion of NALs allows OU to better reflect the community in Oklahoma, the choice to teach entirely outside of the community comes with its own challenges. Like Ojibwe classes at Michigan State University, the placement of these classes at the university removes the classes, instructors, and resources from the community and takes the learning process out of community contexts (Morgan, 2005). However, teaching NALs at institutions of higher education is still important. These classes may not be producing new speakers, but they are producing teaching materials, which preserve and document the languages, and they raise awareness among young adults of the endangered status of NALs. Additionally, these classes recognize NALs as a part of university-level learning, bringing the NAL into a new domain and making it a part of the everyday life of these young adults. The classes show that NALs can be taught at universities and that young nonnative speakers can teach them there.

\section{NALs in Language Learning}

Before understanding the results of this research, the novelty of studying and teaching endangered NALs at the university level must first be emphasized. Partly due to this novelty, the position of these languages in the theory of language learning is still under debate. Arguments have been made to include them in second language learning, heritage language learning, or to create a new model of heritage mother tongue or ancestral language learning (Carreira, 2004; Hinton, 2011; McCarty, 2008; White, 2006). These languages have been put in such a variety of categories because of the diverse situations of the 175 NALs spoken in the United States. Each category is applicable and valuable for some communities. Consider, for example, the different resources available to Cherokee with 8,000 native speakers and Cheyenne with only 20. There are common issues that all Native American communities share, especially the tie to a Native American identity and the pressures of simultaneously preserving and passing on the language. Based on the information gathered through the survey, some of the participants' backgrounds and motivations in this study allow them to be grouped as heritage language learners.

Heritage language learners have a familial connection and/or previous linguistic background with the language, while second language learners (L2Ls) may be anyone learning a language which is not their mother tongue. The term heritage language learner 
(HLL) is just starting to develop a concrete definition, with the debate centering on whether the learner's level of linguistic proficiency or association with an ethnic identity/community is more important in determining his/her status as an HLL. For most language teachers, HLL refers to a student with a previously developed proficiency in the language via their home environment (Valdés, 2001). However, the term is also being applied to NAL learners, many of whom have never or rarely heard their language spoken, but who consider the language to be a deep part of their heritage and identity.

Carreira (2004) offers four categories of HLLs based on different levels of heritage language community involvement, familial background and ancestral connection with the heritage language community, and proficiency in the heritage language. Carreira's four categories describe learners who are defined by their membership in the heritage language community regardless of their linguistic proficiency (HLL1s); learners who are defined primarily by their familial or ancestral background, not by their present primary membership in the heritage language community (HLL2s); learners who are bilingual and defined only by their level of linguistic proficiency (HLL3s); and learners with some knowledge of the heritage language, but whose community membership is often questioned because of their lack of proficiency in the language (HLL4s).

Carreira's four subcategories of HLLs do not exactly line up with the results of this survey, but her three criteria for classifying HLLs based on community membership, familial background, and linguistic proficiency can be used to identify participants in the survey who may have needs more like those of HLLs. The results of the question about previous exposure to the language, in combination with student responses to the question on motivation, can identify a subgroup of students who are taking the course out of a desire to better connect with family or community members who speak the language, who are taking the course because they have Native American ancestry, and/or who have had previous exposure to the language in their home. Students who have any or all of these three traits may be HLLs and this particular subgroup of participants will be given special attention in examining the results of the survey.

The subgroup of HLLs can be further divided into a "narrowly" defined group (those with connections to the NAL community or NAL-speaking family members or previous exposure to the NAL in their home) and a "broadly" defined group (those with only Native American ancestry). These categories are very similar to the narrow and broad categories of HLLs used by Reynolds, Howard, and Deák (2009) in their study of HLLs. Based on their backgrounds and motivations, the narrow HLLs are more likely to be actively involved with the NAL community and are similar to Carreira's HLL1s. The broad HLLs are similar to Carreira's HLL2s and have also been called "learners with a heritage motivation" because they often enroll in language courses to find a connection with their ancestral identity, whereas the narrow HLLs are reinforcing a pre-existing identity (Carreira, 2004).

HLLs are difficult to define because the definition must include the large variety of learners who may be identified as HLLs, and at the same time differentiate HLLs from L2Ls by focusing on their unique needs. NAL learners are also difficult to situate in current language learning paradigms because their situations are so diverse. While they have needs that are similarly unique to HLLs, particularly identity/linguistic needs that stem from their family background (Carreira, 2004), they also have needs unique only to 
learners of endangered languages. NALs are learned by students who have a recent or remote heritage and existing or potential identity connected to the language, which may or may not be spoken in the home or community (or even at all) and which is currently facing endangerment. With this constant threat come certain responsibilities and pressures which only language teachers and learners of endangered languages experience. The following discussion of the results of the survey seeks to categorize NAL students in order to identify the types of learners present in NAL classrooms. Understanding the types of learners in the classroom, and what learning needs these types of learners have, is invaluable to instructors, and specific pedagogical implications are further discussed in detail at the end of this article.

\section{Motivation}

The importance of student motivation in language learning was originally introduced under L2 acquisition theory, but it is also studied in HLLs (see, for example, Reynolds et al., 2009). Motivation is usually described as a combination of effort and desire to achieve the goal or fulfill the need of learning the language, plus favorable perceptions or attitudes towards learning the language, plus a belief in the likely success of learning the language (Gardner, 1985; Saville-Troike, 2006). Most of the previous motivation studies in L2 acquisition and HL learning research have been concerned with commonly taught languages, such as Spanish (Hernández, 2008; Mandell, 2002). In one study with HLLs of nineteen different languages, the researcher found that the desire "to connect with my family" and "to understand my heritage" were key motivators for narrowly defined HLLs, but not for broadly defined HLLs or non-HLLs (Reynolds et al., 2009). Past research has found that L2Ls and HLLs typically have different orientations of motivation, and the results of this study suggest that NAL students similarly have different motivation orientations depending on if they are HLLs and whether they are broadly or narrowly defined HLLs.

In 1959, Gardner and Lambert introduced the integrative and instrumental orientation model of language learning motivation and these have remained important concepts in L2 motivation studies. Integrative motivation describes a student who has a positive opinion of the language and its culture, to the extent that the student may wish to integrate linguistically or culturally with the target language group (Ueno, 2005). Instrumental motivation describes a student who is focused on the practical usefulness of the language or another pragmatic benefit to be attained through studying the language, such as economic or social advancement (Ueno, 2005). Unlike integrative motivation, instrumental motivation does not involve interest or identification with the target language community (Ueno, 2005). The ten motivators included in this survey are divided into instrumental and integrative factors in Table 1 (see Appendix).

White (2006, p. 96) notes that traditional instrumental motivations (academic and economic advancements) do not apply to NAL learners, but I disagree. In order to be applicable to NAL learners, motivators have to be refocused to a more local context. For example, NAL learners may be motivated by local academic advancements such as fulfilling the foreign language requirement. Additionally, one student indicated that she was studying Choctaw because it would be "professionally advantageous," another traditionally 
instrumental motivator, and noted that she believed this to be in the context of seeking a job with the Chickasaw Nation (Choctaw and Chickasaw are closely related languages). Thus, NAL students can be instrumentally motivated in slightly different ways than traditional L2Ls, but still in terms of academic and economic advancements.

\section{Method}

The survey was approved by OU's Institutional Review Board and was distributed and collected by the researcher during the first few weeks of November 2010. Students were informed that participation in the study was voluntary and anonymous, and that participating or not had no effect on their grade. Due to university research restrictions, surveys completed by participants who were under 18 or over 55 were excluded from the results. Students completed the survey during a regular class meeting and typically finished within ten minutes. The full survey can be found at the end of the Appendix.

A total of 273 students enrolled in an NAL class at OU participated in the study. During the fall semester of 2010, Cherokee, Choctaw, and Kiowa classes of the first-, second-, and third-semester levels were offered, though the third-semester Cherokee classes did not participate in the study due to scheduling conflicts with the instructor. All four semester levels of Muscogee Creek were included in the study. Only one Cheyenne class was offered and so only the five students studying Cheyenne at the intermediate level are represented in this study. Table 2 (see Appendix) summarizes the participants by languages and semester levels. The total enrollment of all the NAL classes that participated in the survey was 466 , so $58.5 \%$ of the possible participant pool completed a survey. This is mainly due to the low attendance of students on days that the survey was given. Fifty-two percent of the participants were male, $46 \%$ female, and $2 \%$ chose not to provide a gender. On average, students of NALs are upper-class undergraduates between the ages of eighteen and twenty-two. The Cheyenne students' results are somewhat problematic to analyze because of the small sample size.

The survey consisted of 10 questions. The first three questions of the survey collected demographic information about the students. Questions 4-6 collected information about the students' previous experience with the language and whether the language is used in their home. Questions 7 and 8 were designed to gather information about which classroom activities (lectures, conversation activities, etc.) students feel are their favorites and which they feel they need more of. Question 9 required students to select and rank factors that motivated them to enroll in the NAL class. Finally, the last question of the survey gathered information about students' plans for future study of the language.

Not every survey that was filled out was included due to students not completing the survey or failing to follow the directions. Student responses for Questions 1-6 were tallied and totaled, and percentages for each category summed to $100 \%$. For Questions 7-9, students were allowed to check anywhere from zero to ten responses. The totals for Questions 7 and 8 are not examined in terms of percentages, as the number of responses selected by each student varied. Student responses for Question 9 were tallied according to how each motivator was ranked. Some of the totals for Questions 9 and 10 summed to more than $100 \%$ as some students gave equal ranking to two or more motivators on Question 9 or selected more than one response for Question 10. As students were not 
required to select and rank a minimum number of motivators on Question 9, the number of students who selected a first, second, or third choice varied from the overall number of participants. The majority of respondents only selected one motivator, though some students selected and ranked all ten. Due to the dwindling of the number of respondents as the rankings lowered, only the top three choices are compared in the results. In comparing students' top three highest ranked motivators, the raw scores (and not the percentages) were used to rank and list them as integrative or instrumental.

\section{Results}

The survey was designed to answer six research questions about NAL students. The results to each research question are examined by overall NAL students, by individual languages, and by narrow and broad HLLs. The total HLL population was 135 (49.5\% of the total population), with 72 students $(26 \%$ of the total population) having narrow HLL characteristics and 63 (23\%) having broad HLL characteristics. Given that only 7\% of OU students identified as American Indian or Alaskan Native for the Fall 2010 semester, the number of HLL students in these classes seems relatively high (University of Oklahoma Institutional Research and Reporting).

\section{(1) How much previous formal contact with the NAL do students typically have?}

The overwhelming majority of students studying a NAL have had absolutely no previous formal contact with the language. Only $13.5 \%$ of the total population had any previous formal contact with the language, while $20.8 \%$ of the narrow HLL population and $8 \%$ of the broad HLLs had taken a nonuniversity course in the language. There were only 27 students who reported previous informal contact (hearing the NAL in the home). At OU, only $12 \%$ (32 students) had high school classes in the NAL that they were studying. For the 20082009 school year, NAL classes made up 1.3\% of the total world language classes offered at the secondary level in Oklahoma (Oklahoma State Department of Education, 2009). While $12 \%$ at the university-level is a minority, they are a relatively larger group than the overall population of high school students in NAL classes in Oklahoma.

The Kiowa learners had the largest number of students (12) who had studied the language in high school, and the Cheyenne learners had absolutely no students with previous high school classes in the language. The Cherokee group had nine students, the Choctaw group six students, and the Muscogee Creek group five students who had taken a high school class. Unfortunately, the State Department of Education of Oklahoma does not currently record which languages are taught in the high school (rather, they are all collectively recorded as "NAL"), and so the differences between the individual language groups cannot be analyzed in terms of the popularity of particular NAL classes offered at the high school level with quantitative data from the state (Oklahoma State Department of Education, 2009). However, based on my experience volunteering at the Native American Youth Language Fair, there are more Oklahoman high school language classes in Choctaw than in the other four NALs offered at OU. Kiowa and Cheyenne have at least one high school level language course, so it is unsurprising that no students had high school Cheyenne classes, but it is interesting that so many students were continuing their study of 
Kiowa from high school. Of course, not every class necessarily participates in the language fair, and high school NAL students may be going on to other universities.

Not a single student had ever taken an online course in the language, but only Choctaw currently has an online language course. Only five students had taken a community class and all five of these students fall under the broad definition of HLLs. Four of these students also heard the language spoken at home, meaning they are classified under the narrow definition of HLL. The low numbers of community class students is consistent with Morgan (2005) who, in discussing the Ojibwe program at Michigan State University, noted that university-level NAL learners are typically students with "limited community involvement" (p. 98). Community language classes may attract more students who hear the language growing up (which is unsurprising, as these students are probably more involved in the community). The OU NAL classes do not appear to be attracting a large number of community class students.

\section{(2) Which classroom activities are favored by NAL learners and which do they feel they need more of?}

Collectively, students studying a NAL indicated that they favor classroom activities involving cultural and historical information, conversation, and grammar. The HLL subgroups have the same favorite activities as the total NAL population. Overall, students studying a NAL feel they need more classroom activities involving conversation, cultural and historical information, and grammar. Notice that these are the same activities that they favor, only in a different order. The HLL subgroups feel they need more of the same activities as the overall NAL student population, except they prioritize speaking over grammar. The top three most checked answers for both questions differ only slightly between the individual languages, as shown in Table 3 (see Appendix). That NAL students, and in particular the HLLs, prefer activities involving cultural and historical information could be interpreted as students wanting to connect with the community and learn more about their heritage.

In examining the results of these two questions, it is unclear if students understood the difference between them, as their responses are very similar. In future surveys, these questions will be reworded to make it clear that the first question refers to classroom activities that the student enjoys and feels are effective, while the second question is asking about classroom activities that need more attention, perhaps because they are missing completely or are not often used.

\section{(3) What are the most common factors motivating students to study a NAL at the university level?}

The overall highest ranked motivator of all of the students studying a NAL was "to fulfill the foreign language requirement" (Figure 1 in the Appendix). Over half of the students of all the languages, except for Cheyenne, selected this factor as their number one reason for taking the course, with all of the other factors ranking as the number one choice less than $30 \%$ of the time. The individual Cheyenne results are not discussed for this question, as there was little consensus among the small sampling. 
No clear single factor was the second choice across all of the languages. Rather, considerable variation exists between the languages, as shown in Figure 2 (see Appendix). Some of the individual languages did not even have a clear majority, with two factors gaining the same number of student responses. The Cherokee students selected both "because I have Native American ancestry" and because the language is "easier to learn than other languages" as the top rated second choice motivator. The Choctaw students selected the same motivator for their second choice as for their first choice (to fulfill the language requirement). The Muscogee Creek students selected "because I have Native American ancestry" and the Kiowa group selected because the "classes are easier than other language classes" as their overall second choice motivator. Considered as a collective group regardless of individual languages, the students chose because the "classes are easier than other language classes" as the second most chosen motivator.

As with the second choice, there is no clear overall third choice motivator across all of the languages (Figure 3 in the Appendix). Cherokee students chose because Cherokee "classes are easier than other language classes," while Choctaw and Kiowa both chose because the "language is easier to learn than other languages." Muscogee Creek students chose "to fulfill the foreign language requirement," the same factor as their most common first choice selection. As a collective group, the students chose because the language "is easier to learn than other languages taught at this university" as the most commonly selected third choice motivator.

For HLLs, both subgroups chose as the most commonly selected first choice motivator "to fulfill the foreign language requirement" and as their second choice "because I have Native American ancestry." For the third choice motivator, the groups had different selections. The narrow HLLs chose "to connect with NAL-speaking community members" while the broad HLLs chose because the "classes are easier than other language classes." These subgroups are partially determined by the students' choices of ancestry and speaking with community members as motivational factors, so while it is unsurprising to find these factors, it is interesting to find them so highly ranked (as the HLLs only had to select the factors, not highly rank them).

\section{(4) Are students studying NALs more integratively or instrumentally motivated?}

Grouping the factors as integrative or instrumental allows for the identification of overarching trends across the languages. As shown in Table 4 (see Appendix), the collective majority of the NAL students selected instrumental motivators as their top three choices. Table 5 (see Appendix) additionally shows that the individual languages continue this trend, where all five language groups selected as the top three highest ranked motivators an instrumental factor, though some also gave equal ranking to an integrative factor as well. Only the Muscogee Creek group selected "because I have Native American ancestry," an integrative motivator, as the second choice majority, without an instrumental factor receiving the same ranking. Of the integrative motivators, having Native American ancestry was the second most chosen motivator for three of the NAL groups (Cherokee, Cheyenne, and Muscogee Creek). Both HLL subgroups also chose fulfilling the language requirement as their first choice motivator and having Native American ancestry as their second choice. However, the narrow HLL group chose an integrative factor for their third 
choice and the broad group an instrumental factor. Thus, narrow HLLs may be more instrumentally motivated and broad HLLs more integratively motivated.

\section{(5) How many students have an interest in continuing their study of the language?}

The majority of Cherokee, Choctaw, and Kiowa students only intend to study the language until they fulfill their foreign language requirement (Table 6 in the Appendix). The results from students studying Muscogee Creek are unique, in that less than half of the students only intended to study the language until they had fulfilled the requirement (the lowest percentage of all the languages) and more than $20 \%$ of the students were interested in a minor (the highest of all the languages). Most of the Cheyenne students stated that the fourth semester intermediate Cheyenne class was the last Cheyenne class they would be taking, though the fourth semester may have been the last required course to meet the foreign language requirement. Only one student indicated that $\mathrm{s} / \mathrm{he}$ would pursue a minor in Cheyenne if a minor were available.

As a whole, and by individual languages (except for Muscogee Creek), the majority (over half) of the students studying a NAL at this university only intend to study the language up until the foreign language requirement is met. The narrow HLL subgroup had the highest percentage of students interested in a minor (33\%), though $36 \%$ still intended to only study the NAL until fulfilling the language requirement. The broad HLL group had very little interest in a minor $(9.5 \%)$ and a clear majority interest (65\%) in only studying the language until fulfilling the requirement. The responses provided for this question did not include community opportunities for future language study. Some students (especially HLLs) may have been interested in furthering their NAL study if there were opportunities in their community. Community language classes may be more attractive to some students, especially HLLs, as these classes are free and do not involve formal grading, but they also engage the student directly with the NAL community.

\section{(6) How do student motivations and their intentions or desires for future study interact?}

The majority of the students who chose "to fulfill the foreign language requirement" as their highest rated motivator indicated for their highest ranked future intentions of study that they would only study the target language as far as needed to fulfill the foreign language requirement or that the current course was the last class they would be taking in the language. Other studies, all done with non-NALs, found a similar correlation between students' motivation to study the language because of the university foreign language requirement and their lack of desire to continue their study of the language (Hernández, 2008; Thomas, 2010). The 67 out of 273 students who selected an integrative motivator as their first choice were more likely to indicate that they would be interested in a minor in the language, if one were offered. Thus, there is a correlation between integratively motivated NAL students and choosing to continue the study of the language beyond the basic foreign language requirement, as found with students studying other languages (Hernández, 2008; Thomas, 2010).

For both HLL subgroups, the majority of the students who chose to fulfill the requirement as their first choice motivator indicated that they also only plan to study the 
language until the requirement is fulfilled. However, for narrow HLLs who are primarily motivated by their Native American ancestry or their desire to speak with community members in the language, the majority indicated that they were interested in pursuing a minor in the language. There were no such trends in the broad HLL group, the majority of which intend to only fulfill the requirement regardless of primary motivation. For details about Cherokee, Choctaw, Muscogee Creek and Kiowa students' future studies by highest rated motivators, see Figures 4, 5, 6 and 7 in the Appendix.

\section{Further Discussion}

Overall, students studying a NAL have had relatively little formal contact with the language, and this may account for the surprisingly common misperception that these languages are "easier to learn than other languages." While it is possible that some of the students may have mistakenly identified the language as easy to learn when in fact the classes were easy, as another researcher using a similar survey with Spanish suspected (Mandell, 2002), this survey included an option to check that the classes, not the language, were easier. However, a surprising number of students $(132$, or $48 \%$ of the total participants) seemed to believe that the languages themselves were easier to learn. One student even wrote under the "other" option of Question 6 that "my main motivation for taking this class is that it is insultingly easy." Due to my experience as a teaching assistant in the program, I am not surprised to find this belief so prevalent among the students. This misperception may change as the newer instructors in the program come in with more formal teaching experience. Considering that most of the older instructors gained teaching experience through teaching community classes, where there is no formal grading, students may perceive the classes-and by association the languages-as easier due to the differences in teaching methods and classroom management styles.

The survey was not designed to investigate student attitudes or ideologies concerning NALs. However, as mentioned at the beginning of this article, motivation includes not only the desire to achieve a goal (such as fulfilling the foreign language requirement), but also favorable perceptions or attitudes towards learning the language, plus a belief in the relevance of learning the language. Based on their motivation and comments, some of the students who participated in this survey may have a negative attitude toward learning the NAL. While a few students' comments cannot be generalized to include all students studying a NAL, the attitude behind their comments may explain some of the trends identified in this study (such as the misperception that the languages are "easy"). Previous research has associated integrative motivation with a positive attitude in the classroom (Ueno, 2005), and NAL students overall are not integratively motivated. Additionally, in administering the survey, I observed more than one student make a laughing comment about Question 6, "Do your parents or family members speak at home?" One student even left a comment on the survey referring to the NAL as a "useless language." However, more research is required to investigate student attitudes and perceptions of NALs at OU.

Reynolds et al. (2009) found that HLLs of nineteen non-NALs were more integratively motivated while non-HLLs were more instrumentally motivated. Interestingly, only the narrow HLLs in this study showed to be primarily integratively 
motivated. Additionally, the narrow HLL subgroup had a much higher concentration of students who had taken non-university classes in the language and who would be interested in pursuing a minor in the language. The broad HLL subgroup showed no such trends. In labeling these two groups, the narrow HLL group may be more accurately referred to as endangered heritage language learners. This label reflects their community involvement and/or linguistic background with the NAL. The broad HLLs, as suggested previously, may be best described as learners with a heritage motivation, reflecting their desire to learn more about their ancestry, possibly as a means of indentifying more with the NAL community.

\section{Possible Pedagogical Implications}

Identifying the types of learners in the classroom can help instructors identify and better meet their needs. Other researchers have already proposed recommendations for teaching to the different subtypes of HLLs and to non-HLLs (essentially L2Ls), and their suggestions can be specifically applied to the context of teaching NALs at OU.

The HLLs in the NAL Program have needs that are different from those students who are learning the NAL as a non-heritage second language. Additionally, the narrow and broad HLLs have different needs from each other. For the broad HLLs (nearly half of all the NAL students at $\mathrm{OU}$ ), instructors may want to reinforce their identity and provide them opportunities to interact more with the NAL community. Carreira (2004) suggests validating these learners' right to identify with their ancestry and promote involvement with the HL community by attempting to actively connect these learners with the community. Similarly, Morgan (2005) attributed the success of the Ojibwe program at MSU especially to the involvement of the community, which is emphasized and sought out via language events that bring together the university language learners and native speakers and extends the classroom experience beyond the university. She describes this as "grounding language learning in community life" (p. 100). For narrow HLLs, Carreira (2004) suggests emphasizing the learner's role in "preserving the cultural and linguistic legacy" of his/her community (p. 20). The recommendations of Morgan (2005) and Carreira (2004) to include community involvement and encourage awareness of language endangerment may be particularly relevant to HLLs, particularly the narrow subgroup.

For the non-HLLs (the majority of NAL students at OU), instructors may wish to incorporate more cultural material in an effort to interest students in the language and increase their integrative motivation, as integrative motivation has been associated with oral proficiency in the target language (Hernández, 2008; Thomas, 2010). Activities that promote integrative motivation may include encouraging students to engage with the target language community by interviewing native speakers or inviting speakers to visit the classroom. Hernández (2008) also encourages instructors to use authentic materials and authentic language in the classroom, though this is more difficult for NAL instructors to achieve as endangered languages have fewer resources, fewer speakers, and fewer teaching materials (authentic or otherwise) available to them.

All of these recommendations, for non-HLLs and HLLs alike, advocate creating an active relationship between the students in the university classes and the language community. One way to foster this relationship would be to build a network of support 
between the university, the community, and other instructors and classes similarly working to teach a NAL to adult learners (high school classes and community classes). For example, the university and high school students could be informed about the other NAL classes (e.g., inform high-schoolers about community classes and which universities have the same NAL classes, etc.). Additionally, university and high school students could be invited to visit community classes and vice versa. However, these classes can also be viewed as a resource for the community. Morgan (2005) discusses the university program as a way to create language spaces that are equally important to the community, as they promote language use among community members and provide a specific space for the language to be used. Everyday language use in the community is the goal of most community language classes, and partnering with other adult language instructors to create language events could connect the web of opportunities available through community, high school, and university-level NAL classes. The involvement of the community does not have to remain removed from the university. As Morgan (2005) states, teaching NALs demands "innovative, community-linked forms of instruction" (p. 97).

Being able to study the NAL as a means for fulfilling the university foreign language requirement is a very important motivational factor for many students enrolled in these classes, even those that may be considered narrowly defined HLLs. Recent studies concerning less commonly taught languages have found that when the language programs are included in a university's foreign language requirement, they generally have higher student enrollments (Ueno, 2005). Allowing students studying NALs to fulfill their language requirement is obviously a powerful motivational factor. Future university programs including NALs should be aware of the importance of receiving language requirement credit to these endangered language learners.

\section{Other Limitations}

The wording of some of the questions on the survey may have limited the results. For example, student responses to Question 9 on motivators would have been more comparable had the survey required students to select and rank a specific number (e.g., three) of the factors. However, some students may only be motivated by one of the ten factors, and by allowing the students to choose the number of relevant factors, I believe that the complex, multifaceted, and individual nature of motivation is perhaps more accurately reflected in the results. For example, 44 students who participated in the survey only selected one first choice motivator and did not select or rank any other factors on Question 9 of the survey. Of the 167 students who selected "This course satisfies the university foreign language requirement" as their primary motivator, 36 did not select any other factors, meaning that $21.5 \%$ of students who were primarily motivated to enroll in the NAL course because of their need to fulfill the university requirement felt as though this was the only factor, of the ten provided on the survey, which described why they were taking the course. Had the survey required the students to select a certain number of factors, some students may have been forced to select factors that did not accurately reflect their motivation.

The design of the survey made distinguishing HLLs somewhat ambiguous. For this study, HLLs were primarily identified by their responses to one question about motivators 
and one about language use in their home. However, these questions may not have been direct enough to accurately identify all HLLs. For example, a student may have Native American ancestry but not feel motivated by this fact to take a NAL course, or they may have been exposed to the language frequently outside of their home. Future surveys will include questions to respond to these limitations, particularly in identifying the different subgroups of HLLs, by asking more detailed questions about student backgrounds in terms of previous linguistic exposure, community involvement, Native American ancestry, and linguistic proficiency prior to enrolling in a class.

\section{Conclusion}

More research is necessary on the motivation of students in college level NAL classes. This first survey can conclude that the majority of the students studying NALs at OU are primarily motivated to fulfill the university language requirement, with no intentions to continue their study of the language further. These results are similar to those found by other studies that surveyed students of other more commonly taught non-NALs. The results of this survey additionally indicated that integratively motivated NAL students are less likely to intend to only study the language as far as needed to fulfill the requirement. Students most interested in furthering their study of the language are narrow HLLs, who have had more previous contact with the language and who are more connected with and interested in the NAL community. Increasing all NAL students' contact and involvement with NAL communities may promote integrative motivation and interest in a minor.

Future research can address the best way to meet the unique needs of endangered language learners, especially those who are endangered heritage language learners (narrow HLLs) and those who are learners with a heritage motivation (broad HLLs). However, Native languages are inseparable from their community. Recommendations about increasing integrative motivation in L2Ls (Hernández, 2008), about the success of a NAL program at the university level (Morgan, 2005), and about meeting the needs of different types of HLLs (Carreira, 2004) all endorse increased involvement of and with the target language community. As Oklahoman NALs continue to be taught at the university level, and as their situation in language learning paradigms is explored, the similarities between these learners and other adult language learners, NAL learners, and HLLs must be understood in order to create the most effective forms of instruction.

\section{References}

Carreira, M. (2004). Seeking explanatory adequacy: A dual approach to understanding the term "Heritage Language Learner." Heritage Language Learner, 2(1), 1-25.

Gardner, R. C. (1985). Social psychology and second language learning: The role of attitudes and motivation. London: Edward Arnold.

Gardner, R. C., \& Lambert, W. E. (1959). Motivational variables in second language acquisitions. Canadian Journal of Psychology, 13(4), 266-272.

Haag, M., \& Willis, H. (2001). Choctaw language and culture: Chahta Anumpa. Norman: University of Oklahoma Press. 
Hernández, T. (2008). Integrative motivation as a predictor of success in the intermediate foreign language classroom. Foreign Language Annals, 39(4), 605-617.

Hinton, L. (2008). Learning and teaching endangered indigenous languages. In N. Hornberger \& N. van Deusen-Scholl (Eds.), Encyclopedia of language and education: Vol. 4. Second and foreign language education (pp. 157-168). New York: Springer.

Hinton, L. (2011). Language revitalization and language pedagogy: New teaching and learning strategies. Language and Education, 25(4), 307-318.

Linn, M. S. (2011, April). State of the state: Oklahoma native languages in the 21st century. Presented at the Oklahoma Workshop on Native American Languages. Tahlequah, OK.

Mandell, P. B. (2002). On the background and motivation of students in a beginning Spanish program. Foreign Language Annals, 35(4), 530-542.

Martin, J. B., \& Mauldin, M. (2001). Creek. In J. Garry \& C. Rubino (Eds.), Facts about the world's languages: An encyclopedia of the world's major languages, past and present (pp. 173-176). New York: H. W. Wilson.

McCarty, T.L. (2008). Native American languages as heritage mother tongues. Language, Culture, and Curriculum, 21(30), 201-225.

McCarty, T. L., \& Zepeda, O. (2010). Native Americans. In J. A. Fishman \& O. García (Eds.), Handbook of language and ethnic identity. Vol. 1: Disciplinary \& regional perspectives (2nd ed., pp. 323-339). New York: Oxford University Press.

Morgan, M. J. (2005). Redefining the Ojibwe classroom: Indigenous language programs within large research universities. Anthropology \& Education Quarterly, 36(1), 96103.

Oklahoma State Department of Education Data Services (2009). Data reported by K-12 schools to Oklahoma State Department of Education.

Reynolds, R. R., Howard, K. M., \& Deák, J. (2009). Heritage language learners in first-year foreign language courses: A report of general data across learner subtypes. Foreign Language Annals, 42(2), 250-269.

Saville-Troike, M. (2006). Introducing second language acquisition. New York: Cambridge University Press.

Thomas, J. A. (2010). How do I satisfy the general education language requirement? University students' attitudes toward language study. Foreign Language Annals, 43(3), 531-550.

Ueno, J. (2005). An analysis of learner motivation of less commonly taught languages. Journal of the National Council of Less Commonly Taught Languages, 2, 45-72.

University of Oklahoma Institutional Research and Reporting. Enrollment analysis 2010.

Retrieved from http://www.ou.edu/provost/ir/enrollment-

analysis/Fall2010All.pdf 
Valdés, G. (2001). Heritage language students: Profiles and possibilities. In J. K. Peyton, D. A. Ranard, \& S. McGinnis (Eds.), Heritage languages in America: Preserving a national resource (pp. 37-77). Washington, DC: Center for Applied Linguistics.

White, F. (2006). Rethinking Native American language revitalization. American Indian Quarterly, 30(1/2), 91-109.

\section{Appendix}

\begin{tabular}{l|l}
\multicolumn{1}{c|}{ Instrumental } & \multicolumn{1}{c}{ Integrative } \\
$\begin{array}{l}\text { This course satisfies the university foreign } \\
\text { language requirement }\end{array}$ & $\begin{array}{l}\text { I wish to connect with } \\
\text { of my community }\end{array}$ \\
\hline$\_$is easier to learn than other languages & I have had positive past experience with \\
\hline classes are easier than other language & $\begin{array}{l}\text { I wish to talk with } \\
\text { members of my family }\end{array}$ \\
\hline $\begin{array}{l}\text { classes at this University } \\
\text { wanted to study something friends or }\end{array}$ \\
\hline $\begin{array}{l}\text { I feel it will be professionally advantageous } \\
\text { I have Native American ancestry }\end{array}$ \\
\hline
\end{tabular}

Table 1. Instrumental and Integrative Motivators of the Survey

\begin{tabular}{|l|r|r|r|r|r|} 
& \multicolumn{1}{|c|}{$\begin{array}{c}\mathbf{1}^{\text {st }} \\
\text { semester }\end{array}$} & $\begin{array}{c}\text { 2 } \\
\text { semester }\end{array}$ & $\begin{array}{c}\text { 3 }^{\text {th }} \\
\text { semester }\end{array}$ & semester & TOTALS \\
\hline CHR & 47 & 27 & 0 & 0 & $\mathbf{7 4}$ \\
\hline CHY & 0 & 0 & 0 & 5 & $\mathbf{5}$ \\
\hline CHO & 40 & 19 & 18 & 0 & $\mathbf{7 7}$ \\
\hline MUS & 19 & 14 & 9 & 2 & $\mathbf{4 4}$ \\
\hline KIO & 32 & 23 & 18 & 0 & $\mathbf{7 3}$ \\
\hline TOTALS & $\mathbf{1 3 8}$ & $\mathbf{8 3}$ & $\mathbf{4 5}$ & $\mathbf{7}$ & $\mathbf{2 7 3}$ \\
\hline
\end{tabular}

Table 2. Participants by Semester Level of Study and Language 


\begin{tabular}{|c|c|c|c|c|c|c|}
\hline & Cherokee & Cheyenne & Choctaw & Creek & Kiowa & TOTAL \\
\hline Grammar & 9,31 & 0,3 & 17,27 & 15,17 & 24,25 & $\begin{array}{r}65 \\
103\end{array}$ \\
\hline Conversation & 20,32 & 2,2 & 19,35 & 15,21 & 16,28 & $\begin{array}{r}72 \\
118\end{array}$ \\
\hline Lectures & 1,19 & 0,1 & 6,20 & 0,18 & 5,6 & $\begin{array}{r}12 \\
64\end{array}$ \\
\hline Homework & 1,9 & 0,0 & 2,2 & 3,5 & 0,3 & 6,19 \\
\hline Compositions & 2,4 & 0,0 & 6,5 & 4,3 & 5,3 & $\begin{array}{r}17 \\
15\end{array}$ \\
\hline Listening & 11,15 & 0,2 & 18,29 & 12,13 & 13,21 & $\begin{array}{r}54 \\
70\end{array}$ \\
\hline Speaking & 12,16 & 3,2 & 13,22 & 12,17 & 19,17 & $\begin{array}{r}59 \\
74\end{array}$ \\
\hline Tests & 0,4 & 0,1 & 1,7 & 1,5 & 1,5 & 3,22 \\
\hline Culture & 23,51 & 1,5 & 18,59 & 11,33 & 18,31 & $\begin{array}{r}71 \\
179\end{array}$ \\
\hline Other & 16,12 & 0,0 & 5,5 & 2,7 & 9,7 & $\begin{array}{c}32 \\
31\end{array}$ \\
\hline
\end{tabular}

Table 3. Favorite and Needed Classroom Activities of Students by Language

Note: (Needed, Favorite) 


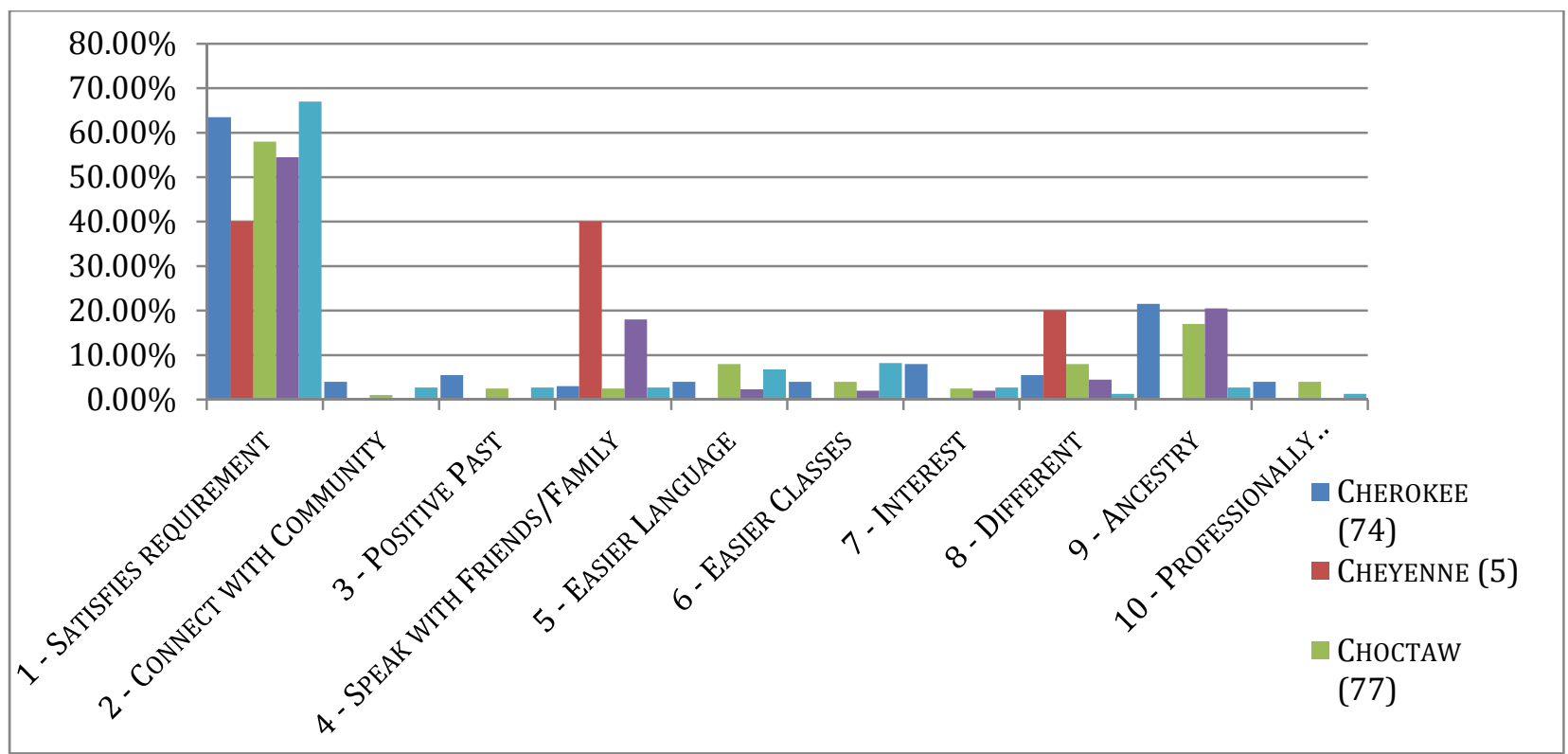

Figure 1. Overall First Choice Motivator by Language

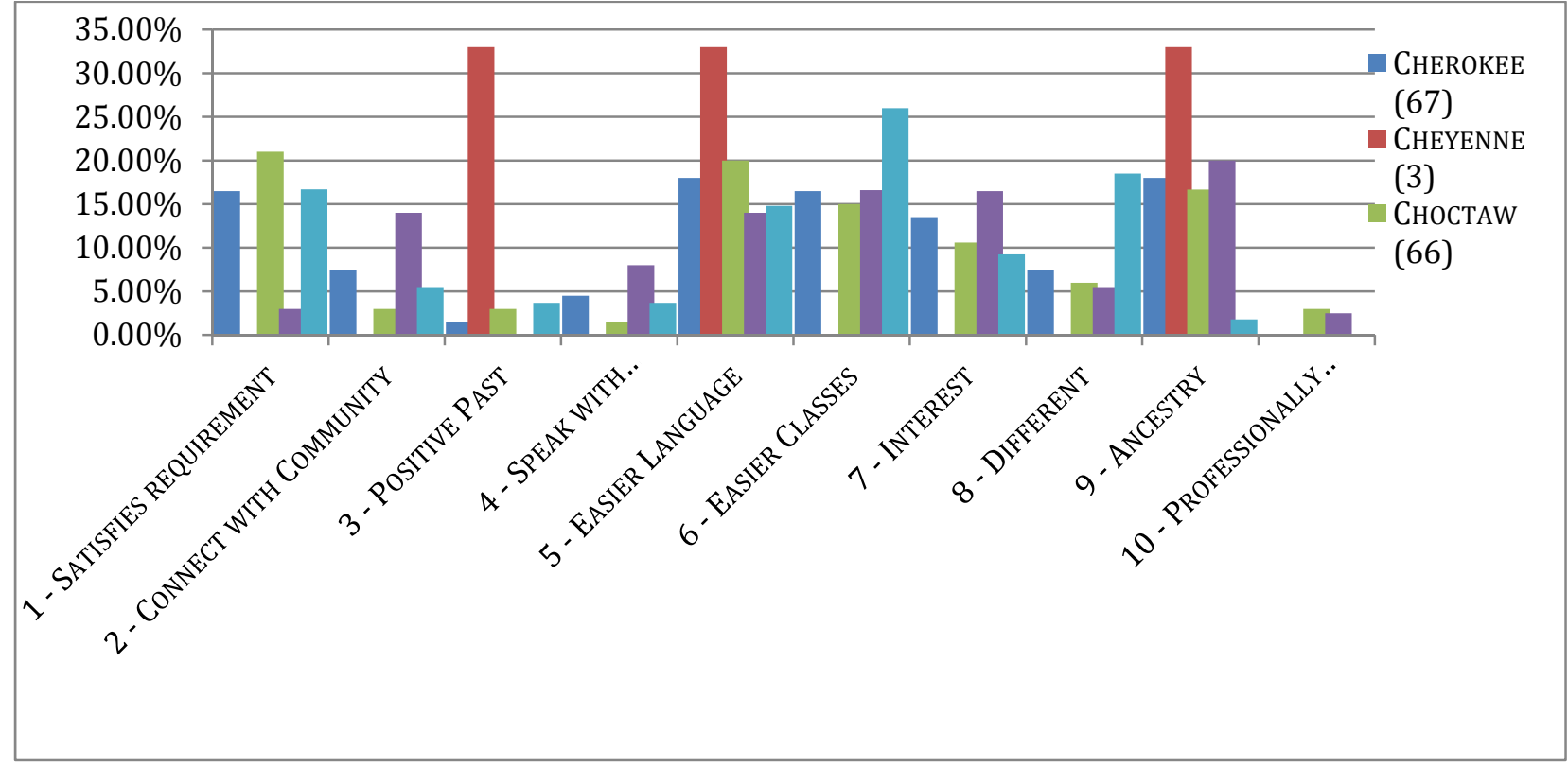

Figure 2. Overall Second Choice Motivator by Language 


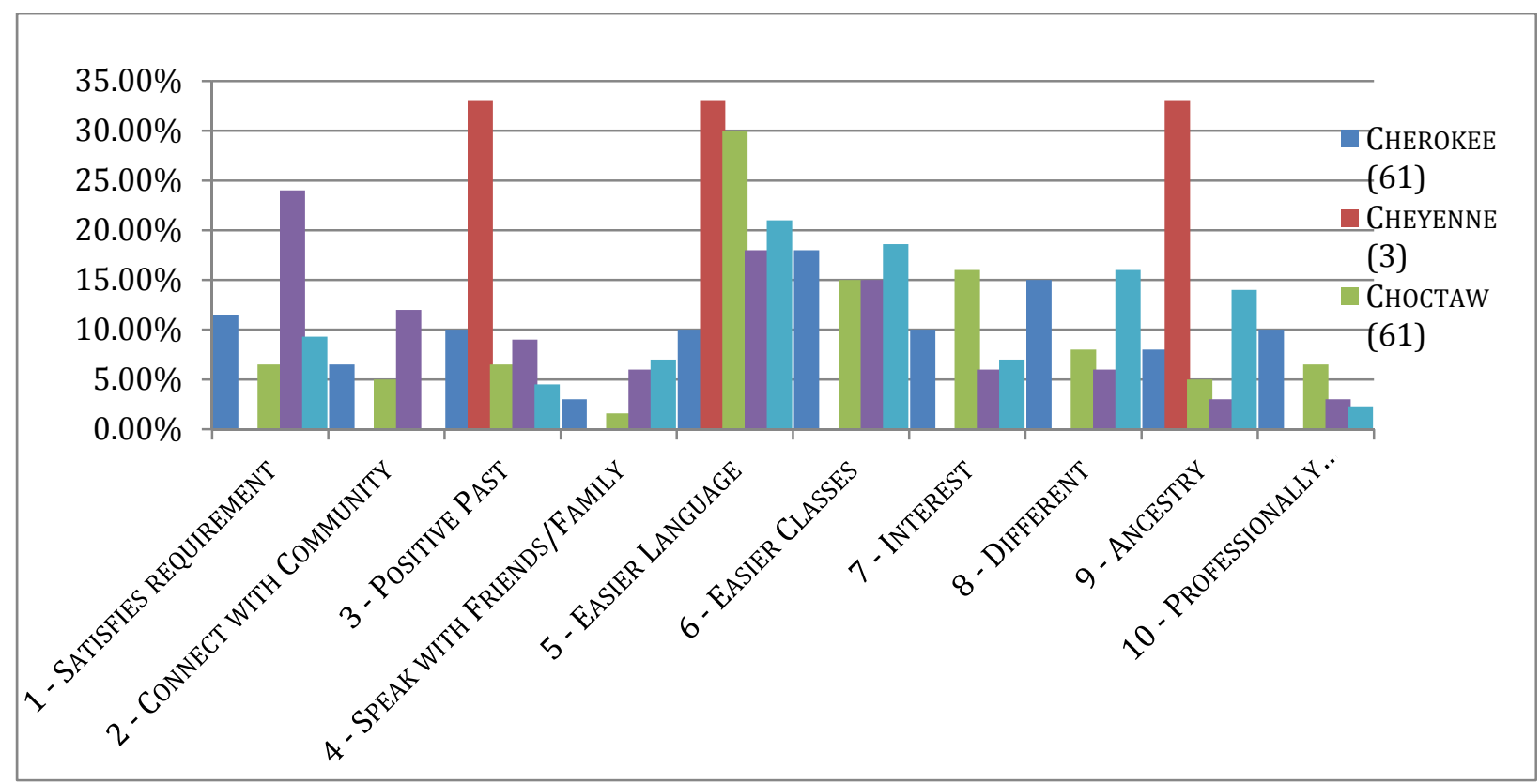

Figure 3. Overall Third Choice Motivator by Language

\begin{tabular}{|lcc|}
\hline & INTEGRATIVE & INSTRUMENTAL \\
\hline $\begin{array}{l}\text { First } \\
\text { Choice }\end{array}$ & - & Satisfies Requirement \\
\hline $\begin{array}{l}\text { Second } \\
\text { Choice }\end{array}$ & - & Easier Classes \\
\hline $\begin{array}{l}\text { Third } \\
\text { Choice }\end{array}$ & - & Easier Language \\
\hline
\end{tabular}

Table 4. Students' Overall Highest Ranked Integrative/Instrumental Motivators 


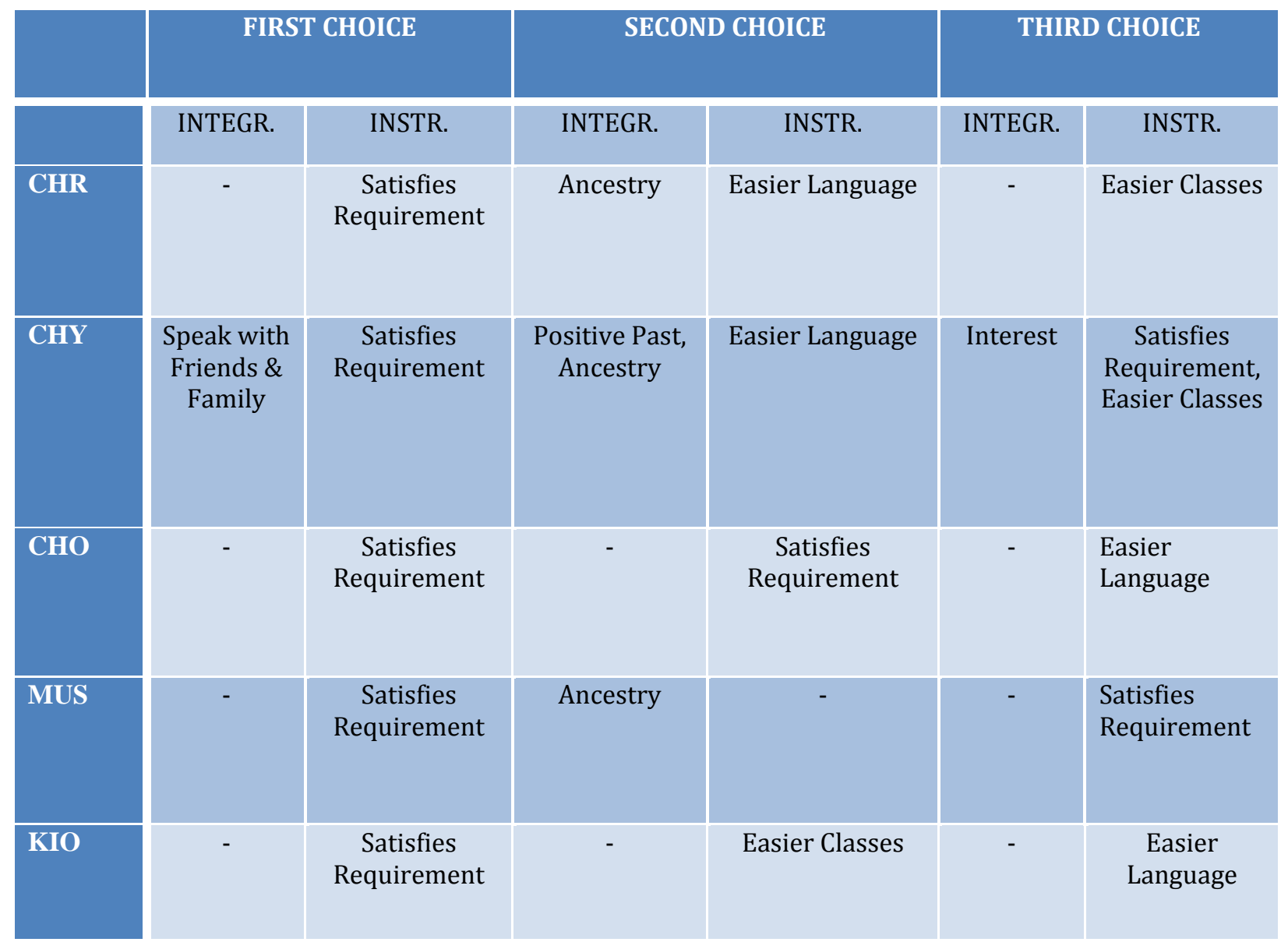

Table 5. Highest Rated Integrative/Instrumental Motivators by Language

\begin{tabular}{|l|c|c|c|c|c|c|c|c|} 
& CHR & CHY & CHO & MUS & KIO & $\begin{array}{l}\text { NARROW } \\
\text { (HLLs) }\end{array}$ & $\begin{array}{l}\text { BROAD } \\
\text { (HLLs) }\end{array}$ & TOTAL \\
\hline FULFILL & $62 \%$ & $0 \%$ & $59 \%$ & $38 \%$ & $52 \%$ & $36 \%$ & $65 \%$ & $55 \%$ \\
\hline LAST & $6 \%$ & $50 \%$ & $15 \%$ & $22 \%$ & $30 \%$ & $12.5 \%$ & $13 \%$ & $18.5 \%$ \\
\hline MINOR & $16 \%$ & $17 \%$ & $12 \%$ & $20 \%$ & $7 \%$ & $33 \%$ & $9.5 \%$ & $14 \%$ \\
\hline UNCERTAIN & $16 \%$ & $33 \%$ & $14 \%$ & $20 \%$ & $11 \%$ & $21 \%$ & $19 \%$ & $16 \%$ \\
\hline
\end{tabular}

Table 6. Students' Future Intentions of Study by Language 


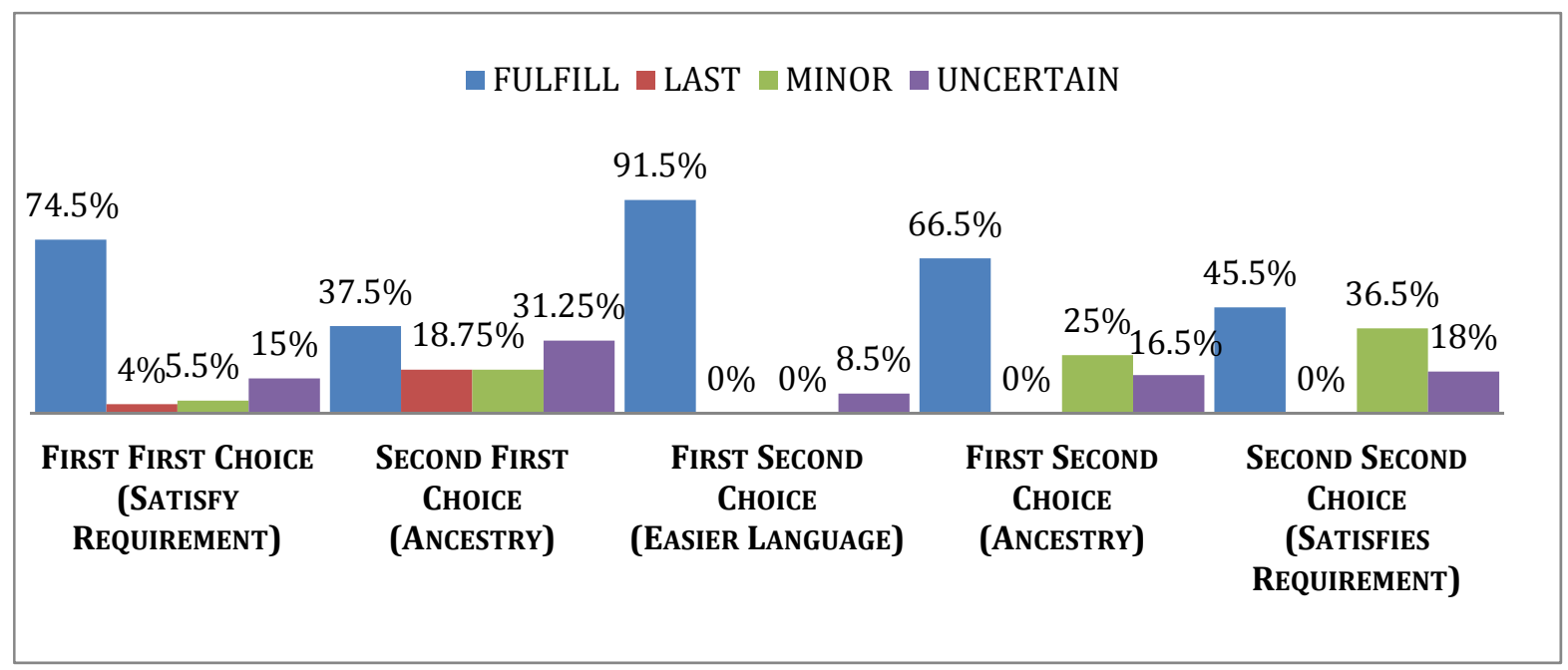

Figure 4. Cherokee Students' Future Intentions of Study by Highest Rated Motivators

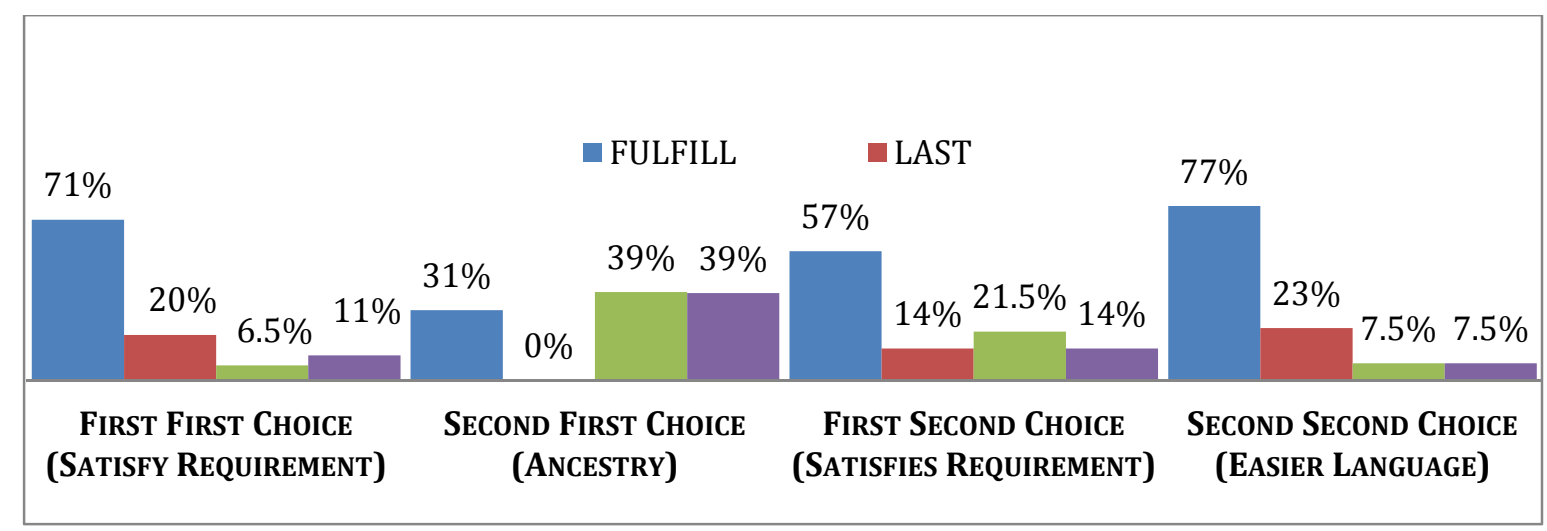

Figure 5. Choctaw Students' Future Intentions of Study by Highest Rated Motivators

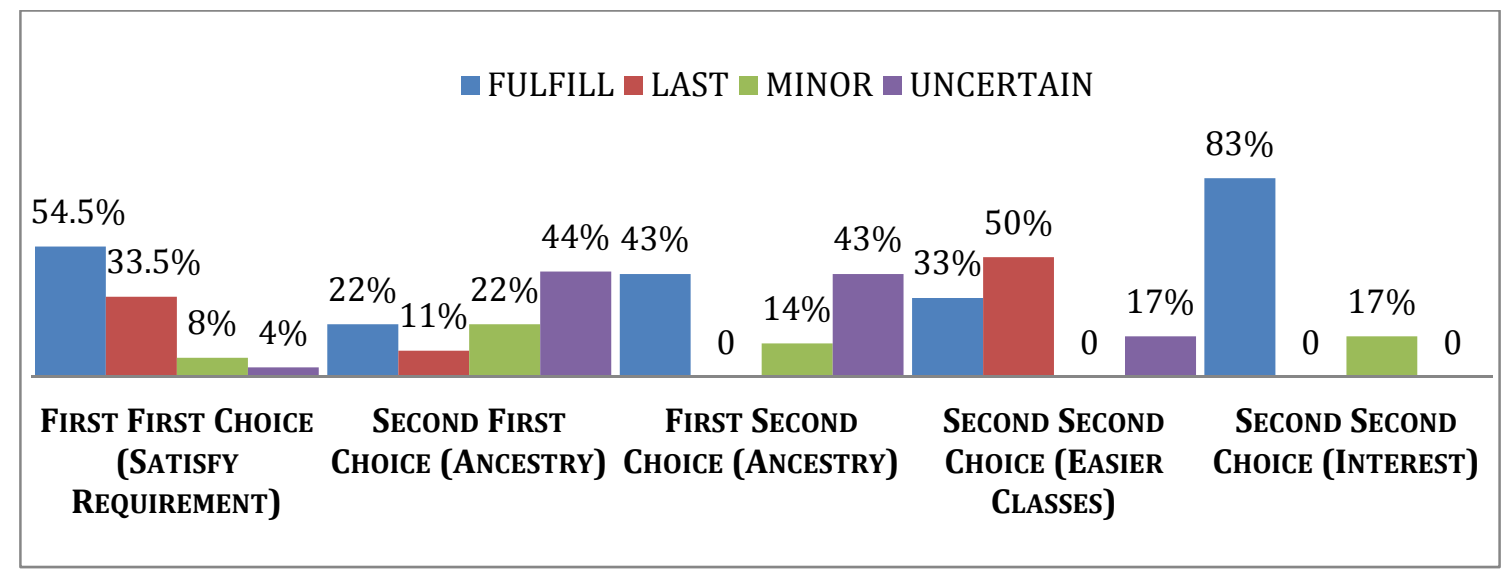

Figure 6. Muscogee Creek Students' Future Intentions of Study by Highest Rated Motivators 


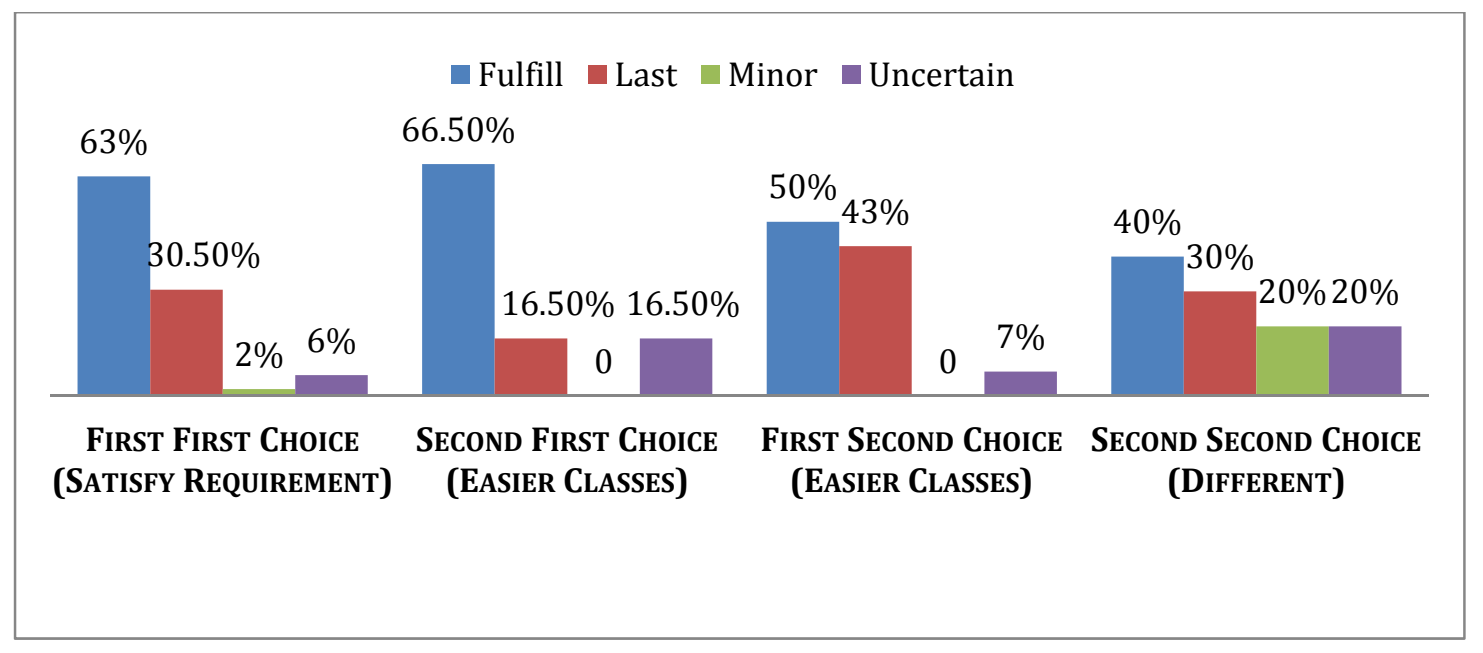

Figure 7. Kiowa Students' Future Intentions of Study by Highest Rated Motivators

\section{Model Questionnaire Administered to the NAL Classes (with truncated spacing)}

(Note: Blanks were filled in with the specific language of each class)

\section{General Information}

1. Level at the University: $\square$ freshman $\square$ sophomore $\square$ junior $\square$ senior $\square$ graduate

2. Sex: $\square$ Male $\square$ Female

3. Age: $\square$ Less than $18 \square$ 18-22 $\square$ 23-27 $\square$ 28-32 $\square$ 33-40 $\square$ 40-55

\section{Language Background}

4. Non-University language classes taken (circle): 1 yr high school, 2 yrs high school, 3 yrs high school, 3+yrs high school, no previous experience, community classes, online classes 5. University-level __ classes taken, if applicable (circle): 1 semester, 2 semesters, 3 semesters, $3+$ semesters

6. Do your parents or family members speak at home? (circle): Always Usually Occasionally Never

\section{Course}

7. My favorite part of this course is (check all that apply):

$\square$ grammar explanations/exercises $\square$ conversation activities $\square$ lectures $\square$ homework

$\square$ compositions $\square$ listening activities $\square$ opportunities to speak with others in class $\square$ tests

$\square$ cultural and historical information $\square$ other:

8. I feel I need more (check all that apply): 
grammar explanations/exercises $\square$ conversation activities $\square$ lectures $\square$ homework

$\square$ compositions $\square$ listening activities $\square$ opportunities to speak with others in class $\square$ tests

$\square$ cultural and historical information $\square$ other:

\section{Motivation}

9. I am taking this course because: (check all that apply to you; if you check more than one, please rank all of your choices in order of importance, with 1=most important)

$\square$ This course satisfies the university foreign language requirement

I wish to connect with -speaking members of my community

I have had positive past experience with

I wish to talk with -speaking friends or members of my family is easier to learn than other languages classes are easier than other language classes at this University

$\square$ I have an interest in foreign languages and other cultures

I studied another language in high school and wanted to study something different in college

I have Native American ancestry

I feel it will be professionally advantageous

\section{Future Study}

10. How far will or would you go in your study of ?

$\square$ This is the last course I will be taking.

I am uncertain.

$\square$ I would pursue a minor in , if it were offered.

$\square$ Only as far as needed to fulfill the foreign language requirement. 